\title{
Evaluation and Prediction of Regional Water Resources Carrying Capacity: A Case Study of Shandong Province
}

\author{
Hongyan Liao ${ }^{1}$, Yuabiao Zhang ${ }^{2}$, Zhifeng Chen $^{2} \&$ Zexin Meng ${ }^{2}$ \\ ${ }^{1}$ Finance Department of International Business School, Jinan University, Zhuhai, China \\ ${ }^{2}$ Packaging Engineering Institute, Jinan University, Zhuhai, China \\ Correspondence: Hongyan Liao, Finance Department of International Business School, Jinan University, Zhuhai, \\ China. Tel: 86-158-2058-1374. E-mail: 812602882@qq.com
}

Received: November 27, 2016

Accepted: December 21, 2016

Online Published: January 9, 2017

doi:10.5539/enrr.v7n1p21

URL: http://dx.doi.org/10.5539/enrr.v7n1p21

\begin{abstract}
Growing pressure on the world's water resources is having major impacts on us. In this paper, we discuss on water resources carrying capacity. We have a case study of Shandong Province which is one of the most arid regions in China. Considering the dynamics of water supply and demand, we combine the Falkenmark indicator and the binary dynamics model to establish an evaluation model of regional water resources carrying capacity. According to the result of our model, Shandong Province is heavily exploited. The per capita water resources in Shandong province were less than $300 \mathrm{~m}^{3}$ in the past ten years. The increasing destruction and increasing waste make the situation even worse. Then ARIMA model and BP neural network is combined to propose a prediction model. We use it to predict the supply and demand of water resources in Shandong Province in the next 15 years
\end{abstract}

Keywords: water resources, carrying capacity, Falkenmark indicator: ARIMA model: BP neural network

\section{Introduction}

Growing pressure on the world's water resources is having major impacts on our life. According to the United Nations, 1.6 billion people (one quarter of the world's population) experience water scarcity. Water scarcity is the lack of sufficient available water resources to meet water needs within a region (Brown, 2011). Water use has been growing at twice the rate of population over the last century. Water is vital for human being. Humans require water resources for industrial, agricultural, and residential purposes. Every community and ecosystem on Earth depends on water for sanitation, hygiene, and daily survival.

There are two primary causes for water scarcity: physical scarcity and economic scarcity. Physical scarcity is where there is inadequate water in a region to meet demand. Indicators of physical water scarcity include: acute environmental degradation, diminishing groundwater, and water allocations that support some sectors over others (Molden, 2007). Economic scarcity is where water exists but poor management and lack of infrastructure limits the availability of clean water. In addition to these two causes, the increasing personal consumption, increasing industrial consumption, increasing pollution and lack of correct management also lead to water shortage.

Since the end of the twentieth century, the calculation methods of carrying capacity have been constantly improved, among which, ecological carrying capacity model and ecological footprint model are the most representative models (Wackernagel \& Rees,1998; Wackernagel \& Onislo, 1997). These models are widely being used in the field of regional sustainability evaluation in China, and the Water Resources Carrying Capacity has become a topic of great debate since 2001 and represents a new academic frontier at present (Liu \& Chen, 2007). And many methods were used to assess the Water Resources Carrying Capacity at present (Yao, Wang \& Jiang, 2002), such as usual tendency prediction method, fuzzy comprehensive assessment model (Chen, Ban \& Zhang, 2008; Gong \& Jin, 2009), main component analysis model (Fu \& Ji, 1999), artificial neural networks model (Liu \& Chen, 2007; Lu, Xu \& Wang, 2009), multi-objective computation model (Fang Hu \& Xu, 2006), system dynamics model (Chen Guo \& Li, 2000; Feng Zhang \& Luo, 2008; Zhu, 2008) matter-element model (Tang \& Zhu, 2006), etc.

In this paper, we study the sources of fresh water and water uses, and we also learn about water crisis. Based on BP neural network and the Dynamic Model, we develop a model that provides a measure of water resources carrying capacity. We have a case study of Shandong Province. According to our model, we predict how its 
water resources carrying capacity will be in 15 years and how does this situation will impact the lives of citizens of this region.

\section{Methodology}

\subsection{A Model for Evaluating Water Resources Carrying Capacity}

In this model, the per capita water resources is used as indicator, and a widely-used measure of water stress proposed by Falkenmark (Brown, 2011) is used to assess the water shortage degree of a region at a certain moment. According to the water shortage degree, the regional water resources carrying capacity can be measured. Considering the total amount of water resources in a region affected by the impact of population growth and the development of industry and agriculture, a binary dynamics model for population and freshwater resources is established to analyze the total quantity change trend in a region in the future for a period of time.

\subsubsection{The Falkenmark Indicator}

From the perspective of the ecological system of the earth, the total amount of water resources is fixed, even becoming less, while the population is increasing with the development of society, resulting less and less water resources per capita in the world, what's worse, some areas have a serious shortage of water.

The Falkenmark indicator (Brown, 2011) is perhaps the most widely used measure of water stress. It is defined as the fraction of the total annual runoff available for human use. Multiple countries were surveyed and the water usage per person in each economy was calculated. Based on the per capita usage, the water conditions in an area can be categorized as: no stress, stress, scarcity, and absolute scarcity (Table 1). The index thresholds $1,700 \mathrm{~m}^{3}$ and $1000 \mathrm{~m}^{3}$ per capita per year are used as the thresholds between water stressed and scarce areas, respectively.

Table 1.Water barrier differentiation proposed by Falkenmark(1989)

\begin{tabular}{cc}
\hline Index $\left(\mathrm{m}^{3}\right.$ per capita $)$ & Category/Condition \\
\hline$>1700$ & No Stress \\
$1000-1700$ & Stress \\
$500-1000$ & Scarcity \\
$<500$ & Absolute Scarcity \\
\hline
\end{tabular}

Set $x_{t}$ as the population in a region in the $t$ year, $y_{t}$ as the total amount of freshwater resources and $O$ as the per capita water resources. Their relationship is as follow.

$$
O_{t}=\frac{y_{t}}{x_{t}}
$$

According to (1), when the population in a region is constant, the less the total amount of freshwater resources is, the less the per capita water resources is. Correspondingly, when the total amount of freshwater resources is fixed, the less the population is, the less the per capita water resources is.

Assuming that fertility policy unchanged of the region and its host country in the next 15 years. The population is

$$
x_{t}=r x_{t-1}
$$

Where $x_{t}$ is the population of a region in the $t$ year, $r$ is the average population growth rate.

\subsubsection{A Binary Dynamics Model}

Based on the system dynamics (Chen, 2006), a nonlinear dynamic model of the evolvement between population and freshwater resources is established. It considers many influence factors, such as population, agriculture and water cycle.

Without considering other resource constraints of the population, population is proportional to population base and the average population growth rate, that is

$$
\frac{d x_{t}}{d t} \propto r x
$$

Where $x_{t}$ is the population of a region in the $t$ year, $r$ is the average population growth rate.

Let $\beta$ be the population that water resources unit can support. Since $y_{t}$ is the total amount of freshwater resources, $\beta y$ the largest population that fresh water resources can support. The population is proportional to the remaining population capacity:

$$
\frac{d x_{t}}{d t} \propto\left(\beta y_{t}-x_{t}\right)
$$


According to Logistic curve, the dynamic model where population changes under the freshwater resource constraint is proposed:

$$
\frac{d x_{t}}{d t}=\alpha x_{t}\left(\beta y_{t}-x_{t}\right)=f\left(x_{t}, y_{t}\right)
$$

As the united nations environment program announced in "Global environment outlook", population growth, industrial development and the expansion of irrigated agriculture are three main element lead to the increasing need of water (The UNEP GEO team, 2000). By correlation analysis, It can be concluded that the development of industry and agriculture is closely related to the population growth. Therefore, the consumption capacity of water resources can be defined as

$$
U=(a+b I+c A) x_{t}
$$

Where $a$ is per capita water consumption, $I$ is industrial output, $b$ is the correlation coefficient of industries and population, $A$ is farmland scale, $c$ is the correlation coefficient of agriculture and population.

Besides, Slobodan P. believes that the amount of water resource is mainly influenced by five factors: population, agriculture, industry, non-renewable resource and continuing pollution (Simonovic, 2002). Non-renewable resource is an influencing factor for industry. In addition, with the development of science and technology, we take sewage purification rate into consideration and propose a dynamics model of water resources change:

$$
\frac{d y_{t}}{d t}=(R+K-U-P) y_{t}=g\left(x_{t}, y_{t}\right)
$$

Where $R$ is water cycling speed, $K$ is sewage purification rate, $P$ is pollution degree.

Since the correlation coefficient of industries and population as well as the correlation coefficient of agriculture and population changes in the degree of industrial and agricultural development in the region, we aim at specific region and get the concrete values for analysis later.

\subsection{Prediction Model Based on Neural Network}

Due to the expansion of industrial scale, the increase of population, the reduction of surface water and other social and environmental factors, the supply and demand of water resources are in a dynamic process of change. In order to better understand the future water situation, the future supply and demand of water resources need to be accurately predicted.

Based on ARIMA model, a prediction model of neural network is established to predict the future supply and demand of water resources. The water demand includes urban living water, industrial water and agricultural water consumption.

\subsubsection{Prediction Model Based on Neural Network}

ZHAO (2014) applied BP neural network model to forecast the water consumption in Shandong Province. Following his model, a prediction model is proposed.

\section{- $\quad$ Establishing a Grid Topology}

Firstly, we determine the structure of the grid topology, including input layer, hidden layer, output layer, number of element and so on. The topology is shown in Figure 1.

As shown in Figure 1, there are $n$ nerve cells in input layer. Input vector is $X=\left(X_{1}, X_{2}, \ldots, X_{n}\right)^{T} \in R^{n}$. There are $l$ nerve cells in hidden layer. Hidden vector is $Z=\left(Z_{1}, Z_{2}, \ldots, Z_{l}\right)^{T} \in R^{l}$. There is only one nerve cell in output layer and the output value is $Y . W_{i j}$ is the connection weight between the nerve cell $i$ in input layer and the nerve cell $j$ in hidden layer. Its threshold value is $\theta_{j}(j=1,2, \ldots, l) . W_{j}$ is the connection weight between the nerve cell $j$ in hidden layer and the output value $Y$. Its threshold value is $\theta_{j}(j=1,2, \ldots, l)$.

- $\quad$ Training the grid

\section{1) Preprocessing sample data}

Before training the grid, the sample data must be preprocessed. One important measure of pretreatment is normalization processing which can be adopted to process the data. The function is:

$$
X_{i}^{*}=\frac{X_{i}-X_{\min }}{X_{\text {max }}-X_{\min }}
$$


Where $X_{i}$ is the value before normalization processing and $X_{i}^{*}$ is the processed value; $X_{\min }$ represents the minimum value; $X_{\max }$ represents the maximum value.

2) Training the grid

The linear transfer function is selected as the neuronal activation function. The processed data is used to train the grid with supervision. The training process is composed of forward and backward propagation.

Step 1: Forward propagation

At the beginning of the forward propagation, all the connection weights are randomly set to a smaller initial value. One sample set is selected as input to the input layer, and then turn to the hidden layer unit, and get the output value of the model in the output layer; At this time, there is a big error between the output value and the expected value.

Step 2: Backward propagation

The change of weight and threshold of each layer is calculated by the backward propagation process. Let the change of threshold be $\square W_{i j}$. After correcting the weights and thresholds of each neuron in the network, the network can be output in accordance with the forward propagation. The error between the actual output value and the expected value generates a new round of weights and thresholds.

Step 3: The forward propagation and backward propagation are repeated until the evaluation error of the system comes to a convergence. At this point, the network coefficients of the corresponding model set can be got and the training process is complete.

3) Making predictions

We make use of the nonlinear mapping ability of BP neural network, adopt the Levenberg-Marquardt back propagation algorithm to predict. The algorithm flow is as follows:

Step 1: standardize the initial data;

Step 2: Use raw data to train the grid;

Step 3: Predict the output value of the $t$ year;

Step 4: Use the data obtained from the forecast in the t year as a sample to train the grid;

Step 5: Let $t$ be $t+1$, return to step 2 until $t=15$.

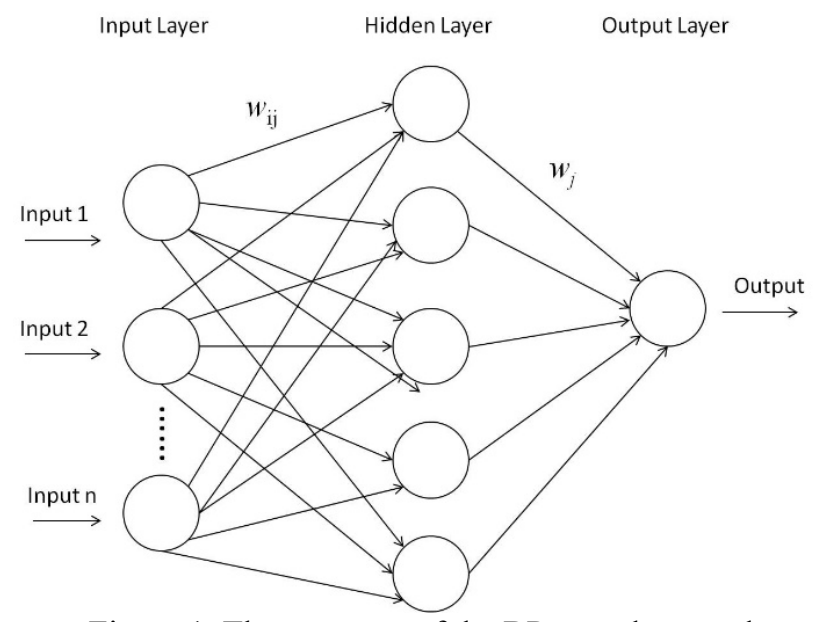

Figure 1. The structure of the BP neural network

\subsubsection{Autoregressive Integrated Moving Average Model (ARIMA)}

Autoregressive Integrated Moving Average Model is actually the expansion of Autoregressive-moving-average model (ARMA). ARIMA model (Wang, 2012) is proposed by Box and Jenkins in 1970, so it is also named Box-Jenkins model. It is used to find the best fit of a time-series model to past values of a time series. In ARMA model, the time series is required to be stationary. But in practice, the time series has a certain trend or cycle characteristics, and cannot meet the requirements of balance. Therefore, the ARMA model cannot be used 
directly. However, if the non-stationary sequence $Z_{t}$ become stationary after the $d$ order by phase difference, the ARMA model can be used to propose a model on the stationary sequence and then the original sequence by inverse transformation can be obtained. The above process is the modeling method of ARIMA. Theoretically, the mathematical description of the ARIMA model is

$$
\Delta^{d} Z_{t}=\theta_{0}+\sum_{i=1}^{p} \phi_{i} \Delta^{d} Z_{t-1}+\varepsilon_{t}+\sum_{j=1}^{q} \theta_{j} \varepsilon_{t-j}
$$

Where $\Delta^{d} Z_{t}$ represents the sequence that $Z_{t}$ turn to after $d$ order by phase difference; $\varepsilon_{t}$ is the random error of $t$ and is an uncorrelated white noise sequence that obeys normal distribution whose mean value is 0 and variance is $\sigma^{2} ; \phi_{i}(i=1,2, \cdots, p)$ and $\theta_{j}(i=1,2, \cdots, q)$ are the estimated parameters of the model; $p$ and $q$ are the orders of the model. From (7), it can be inferred that the ARIMA model is a linear model in essence and its ability of describing the nonlinear characteristics of time series is greatly restricted.

The establishment of ARIMA model includes four steps as follows:

Step 1: Make sure that the variables are stationary, identify seasonality in the dependent series and seasonally differencing it if necessary.

Step 2: Identify the model, mainly by using the autocorrelation plot and the partial autocorrelation plot to identify $p$ and $q$.

Step 3: Estimate the model and diagnose the model. We estimate the parameters of the model and go on significance testing on parameters and randomness testing on residual error. Then we can determine whether the model is desirable.

Step 4: Using the model to predict after selecting appropriate parameters.

\section{Results and Analysis}

Shandong Province in China is selected for case study. Based on the situation of water supply and water demand in Shandong Province in recent ten years, the Falkenmark indicator and a binary dynamics model for population and freshwater resources is used to analyze the ability of Shandong Province to provide clean water to meet the needs of its population. The real data is adopted to further analyze the reason for water shortage.

Considering that the water supply and demand in Shandong Province is in a dynamic process of change, a prediction model of neural network based on ARIMA model is established to predict the supply and demand of water resources in the future 15 years in Shandong Province. The demand of water resources includes urban living water, industrial water and agricultural water consumption. The impact of the water situation on the lives of citizens is also analyzed.

\subsection{Evaluation and Analysis of Water Supply Capacity}

\subsubsection{Evaluate Situation of Water Resources}

Table 2. Statistics of water supply and population by year

\begin{tabular}{cccc}
\hline year & $\begin{array}{c}\text { Total water supply } \\
\left(1 \text { billion } \mathrm{m}^{3}\right)\end{array}$ & $\begin{array}{c}\text { Population } \\
(\text { millions })\end{array}$ & $\begin{array}{c}\text { the per capita water resources }\left(\mathrm{m}^{3}\right. \\
\text { per capita })\end{array}$ \\
\hline 2000 & 24.947 & 89.97 & 277.275 \\
2001 & 25.161 & 90.41 & 278.303 \\
2002 & 25.239 & 90.82 & 277.906 \\
2003 & 21.934 & 91.25 & 240.370 \\
2004 & 21.488 & 91.80 & 234.074 \\
2005 & 21.102 & 92.48 & 228.179 \\
2006 & 22.553 & 93.09 & 242.271 \\
2007 & 21.955 & 93.67 & 234.387 \\
2008 & 21.989 & 94.17 & 233.503 \\
2009 & 21.999 & 94.70 & 232.302 \\
2010 & 22.247 & 95.79 & 232.248 \\
2011 & 22.405 & 96.37 & 232.489 \\
2012 & 22.179 & 96.85 & 229.004 \\
2013 & 21.794 & 97.33 & 223.919 \\
2014 & 21.452 & 97.89 & 219.144 \\
\hline
\end{tabular}


According to water resources supply and population quantity in recent ten years given by Shandong Bureau of statistics (Shandong Bureau of Statistics, 2014), the per capita water resources is calculated as shown in Table 2.

According to water barrier differentiation proposed by Falkenmark, the per capita water resources in Shandong province were less than 500 in the past ten years. It can be known that Shandong Province is absolute scarcity of water resources.

\subsubsection{Analyze the Development Trend of Water Resources}

The binary dynamics model is used to get the stable solution of the system as follow:

$$
\left\{\begin{array} { l } 
{ f ( x , y ) = 0 } \\
{ g ( x , y ) = 0 }
\end{array} \Rightarrow \left\{\begin{array}{l}
A(0,0) \\
B\left(\frac{R+K-P}{a+b I+c A}, \frac{R+K-P}{\alpha(a+b I+c A)}\right)
\end{array}\right.\right.
$$

The stability of the equilibrium state will determine the evolution direction and trend of the system. The future development of ecology and water resources in Shandong Province is discussed by stability analysis theory. The two stable solutions correspond to the respective characteristic root equations. The development trend of the region can be got by analyzing the solution of the characteristic root equation(Liu \& Chen, 2007).

Substitute the statistics in 2014 into the binary dynamics model, It makes sense that $R+K>P$, $\alpha>4(a+b I+c A)$. The first inequality shows that the total effect of sewage purification and self-cycling ability of water in Shandong province is greater than the pollution effect. Over time, water pollution problems can be well controlled and will not cause a vicious circle. The benign effect not only avoids the destruction of ecosystem, but also promotes the surrounding areas. However, the second inequality means that the population growth rate is greater than the water consumption rate that the system can afford. If the rapid growth of population is not timely controlled, the water supply will be insufficient.

\subsubsection{Reasons for Water Scarcity in Shandong Province}

The average amount of groundwater resources in Shandong province for many years is $15.257 \mathrm{billion}^{3}$, the groundwater available yield is 12.593 billion $\mathrm{m}^{3}$. The average amount of fresh water resources in Shandong province for many years is 30.582 billion $\mathrm{m}^{3}$ except the repeated calculation of the mutual conversion between surface water and ground water. From the lack of physical analysis of the reasons for water scarcity in Shandong province, there are several points:

- The total amount of the water resources is insufficient and the per capita possession is low.

With $1.09 \%$ of the total water resources, Shandong Province raises $7 \%$ of the Chinese population and produces $10 \%$ of the country's food. The per capita share of water Shandong Province is only $356 \mathrm{~m}^{3}$, equivalent to $1 / 24$ of the world's per capita share.

- The annual and intra annual drastic changes.

The precipitation and water resources in different parts of Shandong vary from year to year. Wet year and dry year can emerge alternately. It is also common that wet years or dry years emerge continuously.

On the one hand, Shandong Province is a heavily overloaded, on the other hand, increasing destruction and increasing waste lead to the inefficiency of water resources utilization. The primary reasons are as follows:

- Excessively exploit groundwater and damage ecological environment

- The water pollution is serious.

- The utilization rate is low and the waste phenomenon is serious.

Now the process of agricultural irrigation is relatively extensive and the waste of water resources is serious. The recycling rate industrial water is about $50 \%$, while that in the developed countries is $75 \% \sim 85 \%$.

- The retention ability of surface water is weak and the utilization rate is low.

\subsection{Prediction of Future Water Resources in Shandong Province}

In this part, firstly the water supply and demand of Shandong Province in the next 15 years is predicted and later the future water resources combining the future population is analyzed.

\subsubsection{Prediction of Water Supply}

We first analyze the water cycle system of Shandong Province, and explore the source of urban water supply. Then we consider the influence factors of the water supply and predict the supply in the next 15 years. 
- $\quad$ Fresh water cycle in Shandong Province

The total amount of water resources in a region is composed of surface water, soil water and ground water. Precipitation is a supplement to the water resources. The process of human activities cannot be separated from water. Industrial water, agricultural water and domestic water are all derived from nature.

Human use fresh water, and then discharge them to nature through the sewage purification. For the total amount of water resources on the earth has not changed, the sewage is increasing, available clean water is decreasing because of the human activities. The water cycle (Gleick, 1993) influenced by human is as shown in Figure 2.

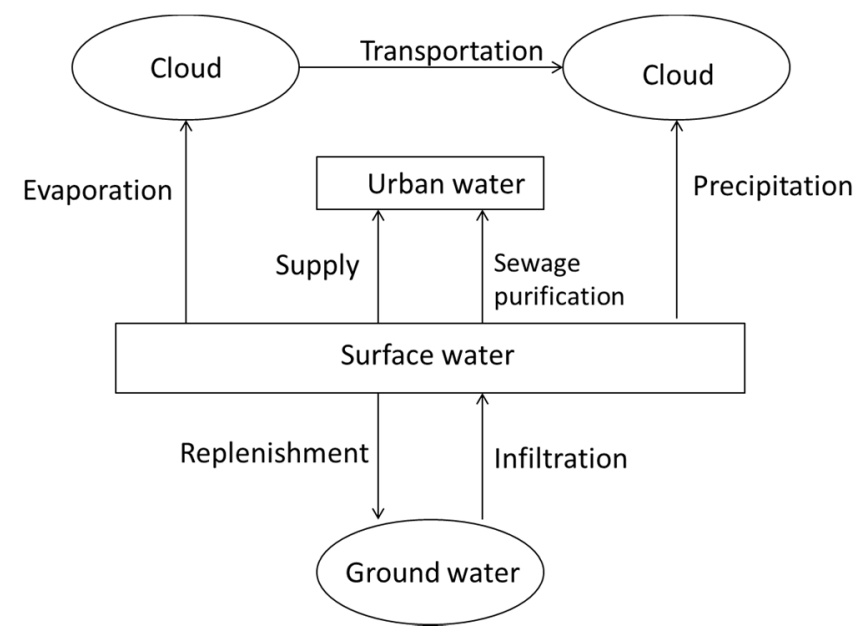

Figure 2. The water cycle influenced by human

- $\quad$ Prediction of fresh water supply in Shandong Province

In order to know the situation of water supply in the future, the prediction model of neural network based on ARIMA model is used to predict it in Shandong Province.

The supply of water resources $S_{t}$ is influenced by many factors. The surface water and ground water are direct acting factors. The surface water and ground water will increase in regions where the precipitation is large. The pollution degree of water resources is another important factor. The increasing Sewage will decrease the available clean water.

Therefore, the amount of surface water, groundwater, rainfall and sewage can be used as the input layers of neural network and water supply as the output layer.

According to relevant data of Shandong Province in $2000-2014$, the prediction model is used to predict the industrial water consumption of Shandong Province in the next 15 years, and the results are shown in Figure 3.

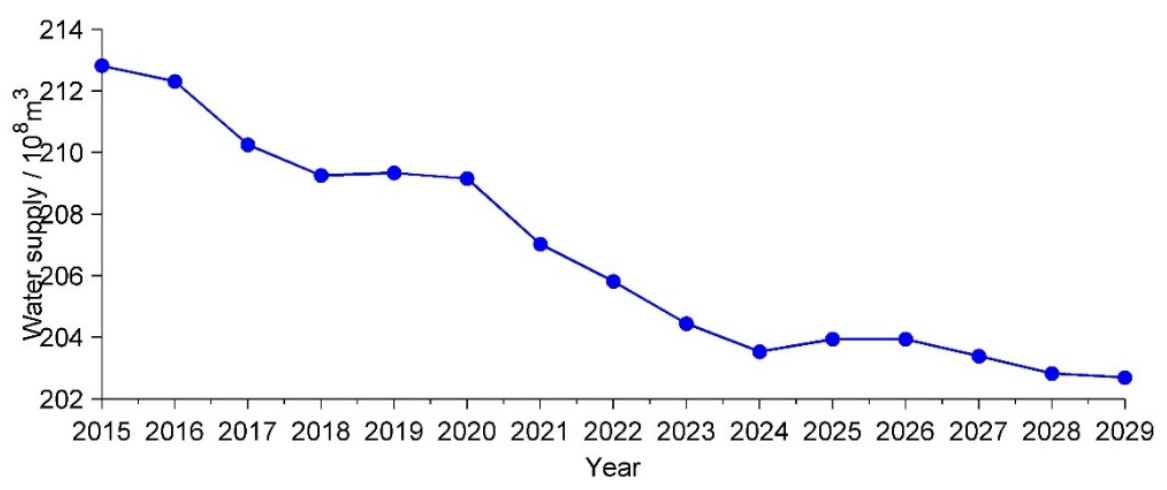

Figure 3. The industrial water consumption of Shandong Province in the next 15 years 
The maximum residual error is 1.3 , and the average prediction accuracy is $98.71 \%$, which indicates that the model has high accuracy.

From Figure 3, it is shown that the trend of water supply is declining, and there will be a quickly decrease in 2020. By 2029, the amount of water will drop to less than 20.3 billion cubic meters, 1 billion cubic meters less than 2015.

\subsubsection{Prediction of the Water Demand in Shandong Province}

The situation of water in a region cannot be fully described only from the aspect of water supply. Therefore, the water demand in Shandong Province for the next 15 years should be forecast, and then the result can be properly analyzed. The water demand contains industrial water $G_{t}$, agricultural water $A_{t}$ and domestic water $C_{t}$, we will forecast them in order to get a better prediction.

- $\quad$ Prediction of industrial water

We analyze the factors that influence the industrial water demand. Finally, we identified three indicators as the input layer of neural network, including the gross industrial output value, the number of important scientific and technological achievements as well as heavy industrial output value. Output layer is industrial water demand.

By using relevant data of Shandong Province in 2000 -2014, we use the prediction model to predict the industrial water of Shandong Province in the next 15 years, and the results are shown in Figure 4.

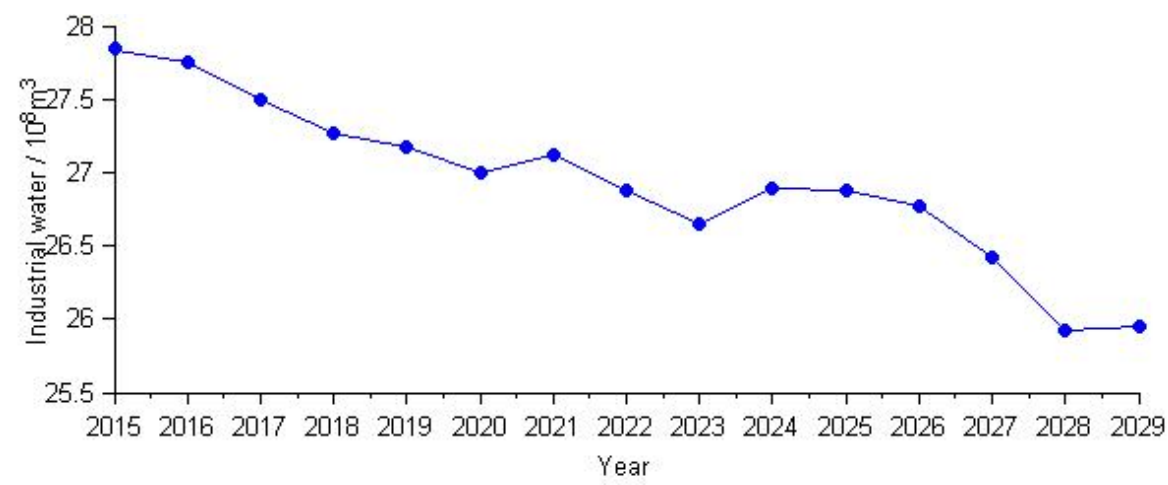

Figure 4. The industrial water of Shandong Province in the next 15 years

The maximum residual error is 1.3 , and the average prediction accuracy is $97.50 \%$, which indicates that the model has high accuracy.

It is shown in Figure 4 that the trend of industrial water is declining, and there will be a small increase in 2020 and 2023.

The higher the output value of the industry is, the more water is used. However, with the improvement of science and technology, the utilization of water will increase, and then industry water will reduce.

\section{- Prediction of agriculture water}

The main factors of agricultural water consumption are farmland irrigation area, total agricultural output value, crop sown area.

We forecast the farmland irrigation area, total agricultural output value and sown area of crops separately in order to get a better agriculture water prediction. The three factors above will be as the input layer of the neural network, the agriculture water consumption as the output layer.

According to the relevant data of Shandong Province in 2000 -2014, the prediction model is used to predict the per-capita water use of Shandong Province in the next 15 years, and the results are shown in Figure 5. 


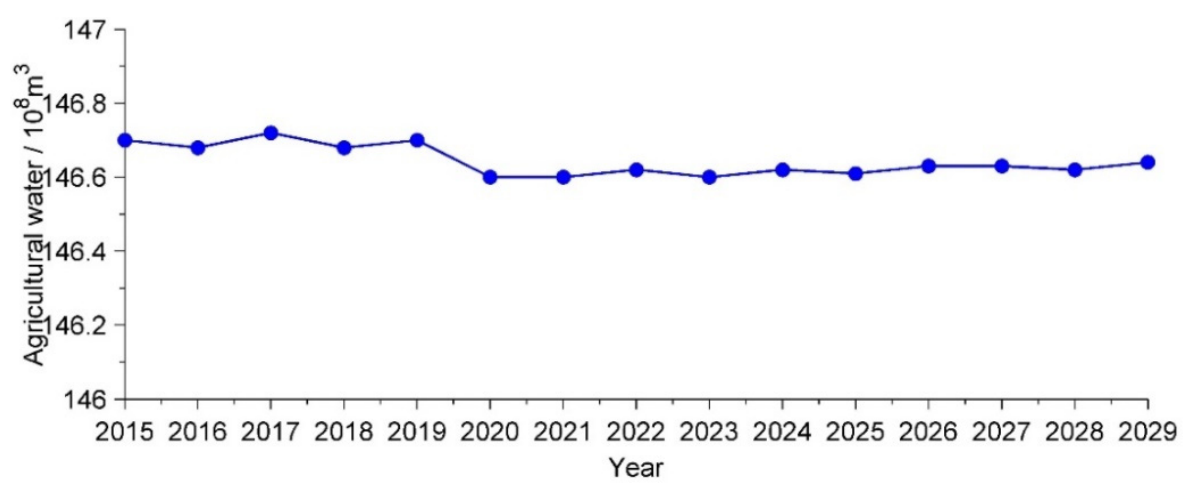

Figure 5. the per capita water use of Shandong Province in the next 15 years

The maximum residual error is 1.3 , and the average prediction accuracy is $96.25 \%$, which indicates that the model has high accuracy.

It is shown in Figure 5 that the agricultural water in the next period of time are stable at around 14.67 billion cubic meters.

- Prediction of domestic water

We forecast the population quantity and per capita water consumption separately in order to get a better domestic water prediction.

\section{- Prediction of population}

Assuming that the natural population growth rate is constant, we predict the population in the next 15 years. The results are showed in Figure 6.

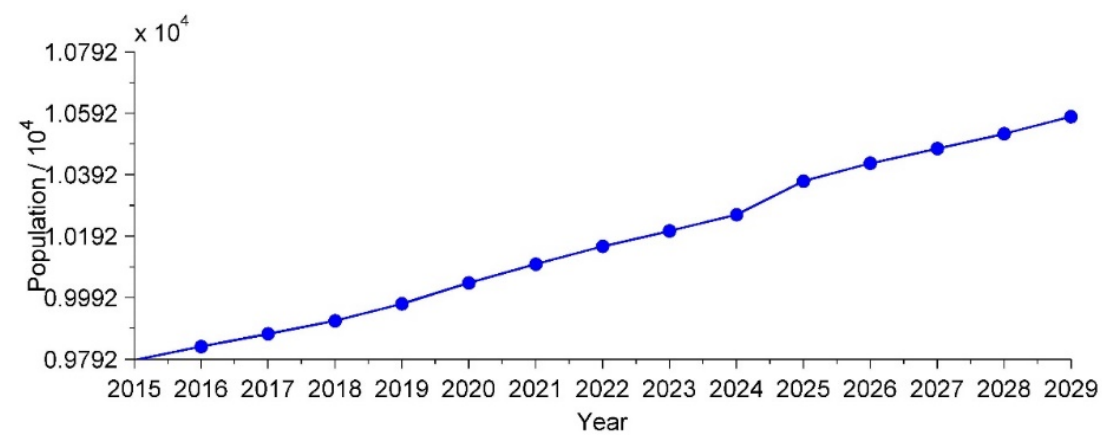

Figure 6 . The population in the next 15 years

\section{- $\quad$ Prediction of per capita water use}

The factors affecting the per capita water consumption are divided into two categories: economic level and living conditions. The former is measured by per capita industrial and agricultural output and per capita disposable income, and the latter is measured by per capita industrial waste water discharge, per capita construction area and per capita afforestation area. The living conditions will be used for predicting per-capita water use.

Per capita industrial waste water emissions, per capita construction area and per capita afforestation area will be as the input layer of the neural network, the per capita water consumption as the output layer

According to the relevant data of Shandong Province in 2000 -2014, the prediction model is used to predict the per-capita water use of Shandong Province in the next 15 years, and the results are shown in Figure 7.

The maximum residual error is 2.1 , and the average prediction accuracy is $97.70 \%$, which indicates that the model has high accuracy.

With the development of economy and society, the per capita water consumption is slowly increasing. However, coupled with the increase in the number of people, the future of living water will be very large. 


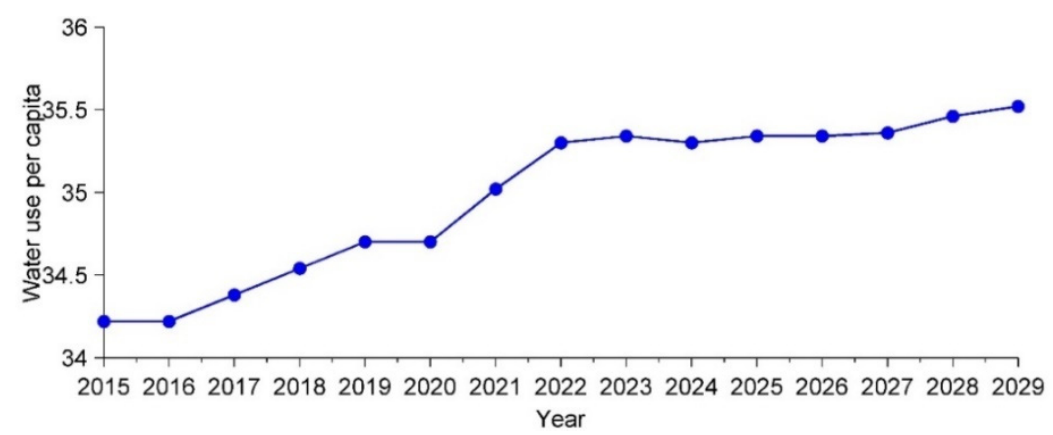

Figure 7. The per-capita water use of Shandong Province in the next 15 years

- Prediction of Total domestic water consumption

Total domestic water consumption $C_{t}$ can be calculated by the following formula:

$$
C_{t}=\text { per }_{t}^{*} \text { pop }_{t}
$$

Where per $_{t}$ and pop $_{t}$ is per-capita water use and population in $t$ year.

Total domestic water consumption in the next 15 years are shown in Figure 8.

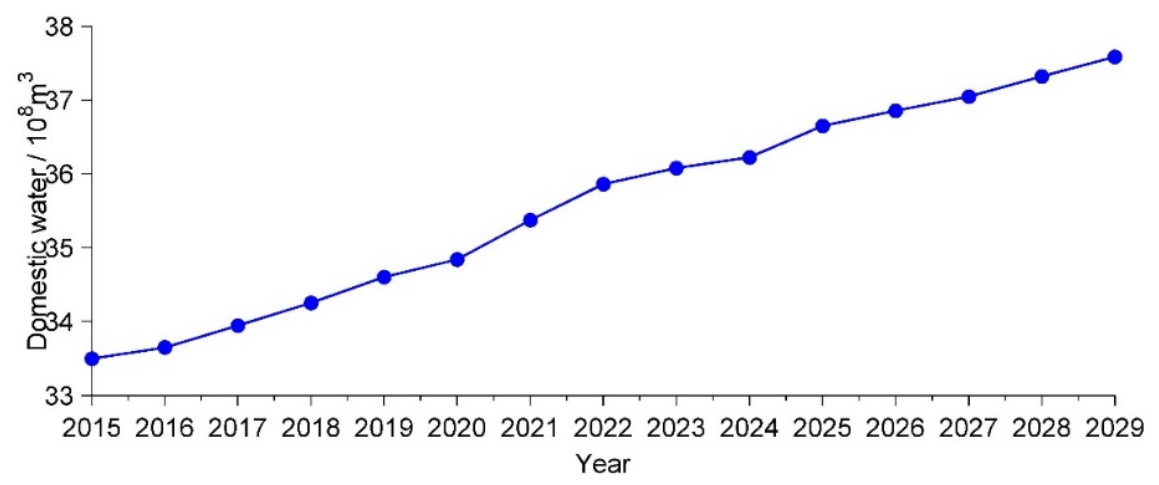

Figure 8 . Total domestic water consumption in the next 15 years

\subsubsection{Future Water Condition Analysis}

Based on the above data and analysis, the supply and demand of water resources in the next 15 years are shown in Figure 9.

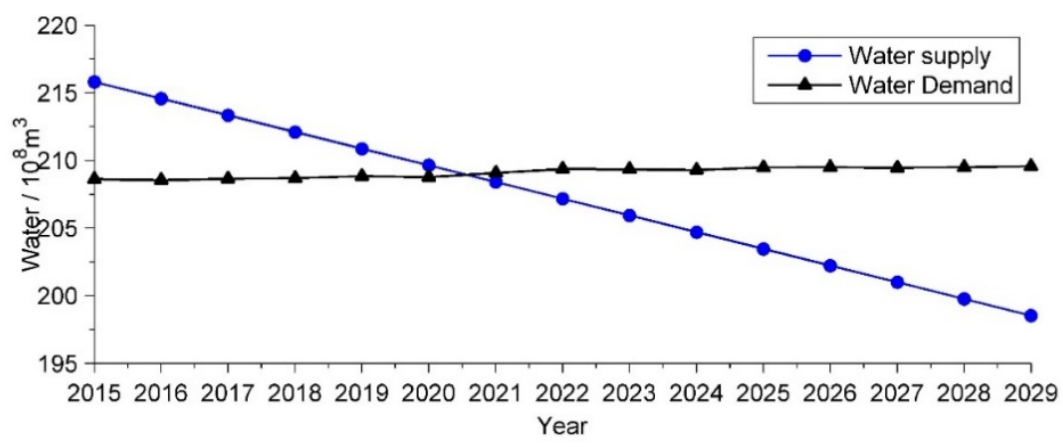

Figure 9. The supply and demand of water resources in the next 15 years 
From the image above shows that the region's future demand for water resources is not changing, with an extremely slow rate of increase, while the supply of water resources to a relatively rapid decline. If the relevant measures are not taken, in 2020, the region's demand for water resources will be greater than the supply, so that the city into the water resources crisis.

It is known to all that the most closely related to the life of the residents is the water. In order to thoroughly analyze the future life of the residents of the region, the future of all aspects of water need to be analyzed. Detailed water conditions in Shandong in the next 15 years are shown in Table 3.

Table 3. Water conditions in Shandong in the next 15 years

\begin{tabular}{cccccc}
\hline Year & $\begin{array}{c}\text { Water supply } \\
\left(10^{8} \mathrm{~m}^{3}\right)\end{array}$ & $\begin{array}{c}\text { Water demand } \\
\left(10^{8} \mathrm{~m}^{3}\right)\end{array}$ & $\begin{array}{c}\text { Industrial water } \\
\left(10^{8} \mathrm{~m}^{3}\right)\end{array}$ & $\begin{array}{c}\text { Agricultural water } \\
\left(10^{8} \mathrm{~m}^{3}\right)\end{array}$ & $\begin{array}{c}\text { domestic water } \\
\left(10^{8} \mathrm{~m}^{3}\right)\end{array}$ \\
\hline 2015 & 215.81 & 208.62 & 28.42 & 146.70 & 33.50 \\
2016 & 214.57 & 208.53 & 28.20 & 146.68 & 33.65 \\
2017 & 213.34 & 208.65 & 27.98 & 146.72 & 33.95 \\
2018 & 212.10 & 208.69 & 27.76 & 146.68 & 34.25 \\
2019 & 210.87 & 208.84 & 27.54 & 146.70 & 34.60 \\
2020 & 209.64 & 208.76 & 27.32 & 146.60 & 35.84 \\
2021 & 208.40 & 209.07 & 27.10 & 146.60 & 35.86 \\
2022 & 207.17 & 209.36 & 26.88 & 146.62 & 36.08 \\
2023 & 205.93 & 209.34 & 26.66 & 146.60 & 36.22 \\
2024 & 204.70 & 209.28 & 26.44 & 146.62 & 36.65 \\
2025 & 203.46 & 209.48 & 26.22 & 146.61 & 36.86 \\
2026 & 202.23 & 209.49 & 26.00 & 146.63 & 37.05 \\
2027 & 200.99 & 209.46 & 25.78 & 146.63 & 37.32 \\
2028 & 199.76 & 209.50 & 25.56 & 146.62 & 37.58 \\
2029 & 198.53 & 209.56 & 25.34 & 146.64 & \\
\hline
\end{tabular}

It is shown in Table 3 that the total water demand is increasing at a slow speed. After 15 years, the total water demand has only increased by less than 100 million cubic meters. In contrast, the region's water supply to a faster rate of decline, while the population has a certain amount of growth, as shown in Figure 10, in the end to the per capita water share of the rapid decline.

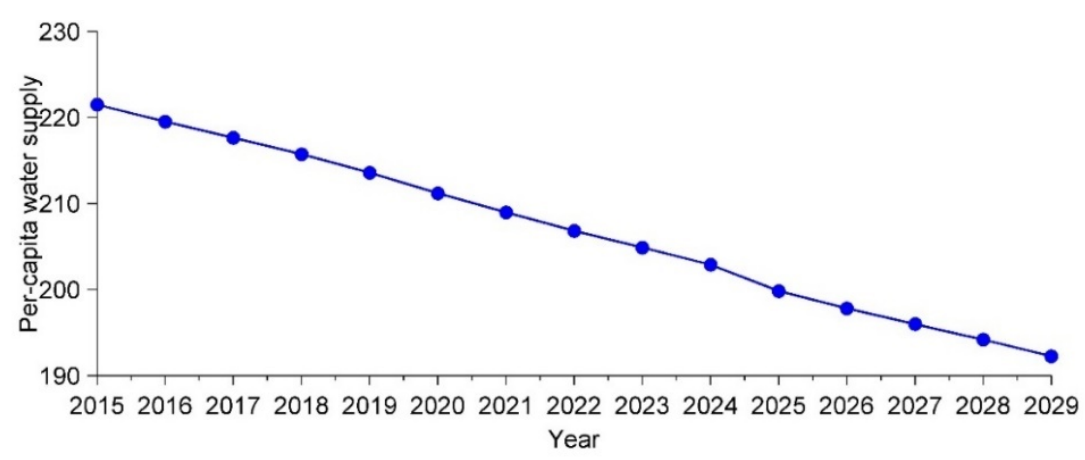

Figure 10. The per capital water supply in the next 15 years

From the part of the water demand, agricultural water will be in a relatively stable state, the industrial water slightly decreased, while the life of water consumption increased significantly. In the case of a sustained reduction in the amount of water supply, water will become increasingly tense, and may even block the supply of water. Therefore, the relevant departments may reduce agriculture water and industrial water be in order to ease the tension of water. However, it will reduce the total output value of agriculture and industry, and hinder the development of the city. 


\section{Conclusion}

With the help of the dynamics model, we establish a model to measure the water resources carrying capacity of a region to provide clean water. Combining ARIMA Model and Neural Network Model, we predict what the water resources carrying capacity will be in Shandong Province. The total effect of sewage purification and self-cycling ability of water in Shandong Province is greater than the pollution effect. Over time, water pollution problems can be well controlled and will not cause a vicious circle. The benign effect not only avoids the destruction of ecosystem, but also promotes the surrounding areas. However, the population growth rate is greater than the water consumption rate that the system can afford. If the rapid growth of population is not timely controlled, the water supply will be insufficient in Shandong Province. The prediction of water resources carrying capacity of Shandong province in the next 15 years shows that the water demand will grow while the water supply will be less. Without taking relevant measures, the water resources in Shandong Province will be unable to meet the needs of the population in 2020. After analyzing the water situation in Shandong Province, we also find the reasons for its water scarcity which include the shortage of total water resources, the large population and the serious pollution, etc.

\section{References}

Brown, A. (2011). A Review of Water Scarcity Indices and Methodologies. The Sustainability Consortium.

Chen, B., Li, L.-J., \& Guo, H. C. (2000). System Analysis on Water Resouces Supporting Alternatives for Chaidamu Basin. Chinese Journal of Environmental Science, 21(3), 16-21. Retrieved from http://en.cnki.com.cn/Article_en/CJFDTOTAL-HJKZ200003003.htm

Chen, L.-L. (2006). Study of Human Activities and Freshwater Resources Based on the Dynamic Model. Research of Soil and Water Conservation, Aug. http://doi:10.3969/j.issn.1005-3409.2006.04.075

Chen, N.-X., Ban, P.-L., \& Zhang, W.-B. (2008). Fuzzy evaluation of the water resources carrying capacity based on the maximum entropy theory. J Irrig Drain, 27(2), 57-60. https://doi.org/10.1109/rsete.2011. 5964734

Fang, G.-H., Hu, Y.-G., \& Xu, Y. (2006). Research on the multi-objective evaluation model of regional water resources carrying capacity and its application. Water Resour Protect, 22(6), 9-13. https://doi:10.3969/ j.issn.1004-6933.2006.06.003

Feng, L.-H., Zhang, X.-C., Luo, G.-Y. (2008). Application of system dynamics in analyzing the carrying capacity of water resources in Yiwu City, China. Mathematics and Computers in Simulation, 79(3), 269-278. http://dx.doi.org/10.1016/j.matcom.2007.11.018

Feng, S.-M. (2010). A forecast method for trip production based on BP neural network. Journal of Harbin Institute of Technology. http://doi:10.11918/j.issn.0367-6234.2010.10.023

Fu, X., \& Ji, C.-M. (1999). A comprehensive evaluation of the regional water resources carrying capacity-application of main component analysis method. Resources and environment in the Yangtze basin, 8(2), 168-173. Retrieved from http://en.cnki.com.cn/article_en/cjfdtotal-cjly199902011.htm

Gleick, P. H. (1993). Water in crisis: a guide to the world's fresh water resources. Oxford University Press, Inc. https://doi.org/10.2307/2623756

Gong, L., \& Jin, C. (2009). Fuzzy comprehensive evaluation for carrying capacity of regional water resources. Water resources management, 23(12), 2505-2513. https://doi.org/10.1007/s11269-008-9393-y

Huang, J. (2009). Agricultural water consumption trend and its influence factors in Beijing over the past 20 years. Journal of China Agricultural University. http://doi:10.3321/j.issn:1007-4333.2009.05.017

Liu, S.-F., \& Chen, J.-H. (2007). Water resources carrying capacity based on the theory of ANN. Res Sci., 29(1), 99-105. http://doi:10.3321/j.issn:1007-7588.2007.01.015

Lu, F., \& Xu, J., \& Wang, Z. (2009). Application of GA optimized wavelet neural networks for carrying capacity of water resources prediction[C]//Environmental Science and Information Application Technology, 2009. ESIAT 2009. International Conference on. IEEE, 2009(1), 308-311. https://doi.org/10.1109/esiat.2009.59

Molden, D.(2007). A Comprehensive Assessment of Water Management in Agriculture. Internatinoal Water Management Institute. Colombo, Sri Lanka: IWMI.

Shandong Bureau of Statistics. (2014).Shandong Statistic Year Book. Beijing: China Statistics Press.

Shandong Provincial Bureau of Statistics. (2016). Retrieved from http://www.stats-sd.gov.cn/ 
Simonovic, S. P. (2002). World water dynamics: global modeling of water resources. Journal of Environmental Management, 66(3), 249-267. https://doi.org/10.1016/s0301-4797(02)90585-2

Song, X., Kong, F., \& Zhan, C. (2011). Assessment of water resources carrying capacity in Tianjin City of China. Water Resources Management, 25(3), 857-873. https://doi:10.1007/s11269-010-9730-9

Tang, Y.-L., \& Zhu, S.-B. (2006). Application of matter-element model to evaluation of water resources carrying capacity in Xinjiang. Water Resour Protect, 22(3), 490-494. Retrieved from http://en.cnki.com.cn/ Article_en/CJFDTOTAL-SZYB200603011.htm

The UNEP GEO team[R]. (2000). UNEP Global Environment Outlook.

Wackernagel, M. (1998). Rees W. Our ecological footprint: reducing human impact on the earth. New Society Publishers.

Wackernagel, M., Onislo, L, \& Bello, P. (1997). Ecological footprints of nations. International Council for Local Environmental Initiatives.

Wang X. (2012). GDP prediction based on intervention model and BP neural network[A]. Statistics and Decision. http://en.cnki.com.cn/Article_en/CJFDTotal-QZSD200703013.htm

Wang, S.(1991). Discussion on the prediction of urban industrial water consumption. Water supply and drainage in China, 1991.

Wang, S.-W. (2006). Analysis on the degree of water shortage in some areas in Zhejiang Province. Water saving irrigation.

Yao, Z., Wang, J., \& Jiang, D. (2002). Advances in study on regional water resources carrying capacity and research on its theory. Advances in Water Science, 13(1), 111-115. http://doi:10.3321/j.issn:1001-6791.2002. 01.019

Zhao, L. M. (2014). Multivariate Linear Regression and BP Neural Network Model for Per Capita Water Consumption Forecasting Model Research in Shandong Province. Journal of Chongqing University of Technology (Natural Science). https://doi:10.3969/j.issn.1674-8425(z).2014.03.024

Zhu, Y.-Z. (2008). Assessment of water resources carrying capacity: a case study of Zhangye in China. 3rd IASWE/WSEAS international conference on water resources, hydraulic \& hydrology, UK (pp. 145-150). https://doi.org/10.1007/s11269-014-0849-y

\section{Copyrights}

Copyright for this article is retained by the author(s), with first publication rights granted to the journal.

This is an open-access article distributed under the terms and conditions of the Creative Commons Attribution license (http://creativecommons.org/licenses/by/4.0/). 